\title{
Gripe Espanhola e SARS-CoV-2: cem anos de diferença que nos igualam
}

\author{
Spanish Flu and SARS-CoV-2: one hundred years of difference that equals us
}

Gripe Española y SARS-CoV-2: cien años de diferencia que nos igualan

Eric Lucas Trindade ${ }^{1 *}$, laci Gama Fortes ${ }^{1}$.

\section{RESUMO}

Objetivo: Apresentar dados relativos às duas grandes pandemias ocorridas num período de 100 anos de diferença uma da outra: a Gripe Espanhola (1918-1920) e a SARS-CoV-2 (2019 F), impactantes quanto aos aspectos geopolíticos, sociais e biológicos da humanidade, em suas respectivas épocas. Revisão Bibliográfica: A pesquisa mostrou que essas pandemias guardam semelhanças em alguns aspectos, como a rápida propagação do vírus e elevados óbitos; que a SARS-CoV-2 vem pondo à prova os sistemas de saúde mundiais, independente do desenvolvimento das nações e motivando uma corrida entre laboratórios, que se veem provocados a desenvolverem medicamentos e vacinas em curto prazo. Considerações finais: A partir deste estudo, compreende-se que qualquer pandemia tem o dom de causar mudanças no comportamento e padrão de vida das pessoas em razão de efeitos devastadores; e a SARS-CoV-2, em expansão, é o desafio da classe científica atual, que tenta descobrir, se não a cura, ao menos o controle da doença.

Palavras-chave: Pandemias, Gripe espanhola, SARS-CoV-2, Épocas, Comportamento.

\begin{abstract}
Objective: Present relative data for the two big pandemics that occurred on a period of 100 years of difference from each other: the Spanish Flu (1918-1920) and the SARS-CoV-2 (2019 F), impactful for geopolitical, social and biologic aspects of humanity, in their respective times. Bibliographic review: The research has shown that these pandemics have similarities in some aspects, such as the rapid spread of the virus and high deaths; that SARS-CoV-2 have tested global health systems to the test, regardless the development of nations and motivating a race between laboratories, which provoke themselves to develop medicines and vaccines in the short term. Final considerations: From this study, it is understood that any pandemic has a gift of causing changes in people's standard of living due to devastating effects; and the SARS-CoV-2, still expanding, is a challenge for the current scientific class, which seeks to discover, if not the cure, at least to control the disease.
\end{abstract}

Key words: Pandemics, Spanish flu, SARS-CoV-2, Times, Behavior.

\section{RESUMEN}

Objetivo: Presentar datos relacionados con las das grandes pandemias que ocurrieron durante un período de 100 años de diferencia entre sí: la Gripe Española (1918-1920) y SARS-CoV-2 (2019 H), que impactan los aspectos geopolíticos, sociales y biológicos de la humanidad, en sus respectivos tiempos. Revisión de la literatura: La investigación ha demostrado que estas pandemias tienen similitudes en algunos aspectos, como la rápida propagación del virus y el alto número de muertes; que SARS-CoV-2 ha estado probando los sistemas de salud mundiales, independiente del desarrollo de las naciones y motivando una carrera entre laboratorios. Consideraciones finales: De este estudio, se entiende que cualquier pandemia tiene el don de provocar cambios en el comportamiento y nivel de vida de las personas debido a los efectos devastadores; $y$

${ }^{1}$ Centro Universitário Claretiano, Boa Vista - RR. *E-mail: ericctrindade@gmail.com

SUBMETIDO EM: 5/2021

ACEITO EM: 5/2021

PUBLICADO EM: 6/2021 
SARS-CoV-2, aún en expansión, es el desafío para la clase científica actual, que intenta descubrir, si no curar, al menos el control de la enfermedad.

Palabras clave: Pandemias, Gripe española, SARS-CoV-2, Tiempos, Comportamiento.

\section{INTRODUÇÃO}

Ao longo da história da humanidade, grande parte das civilizações presenciou inúmeros desastres biológicos, e com as epidemias não foi diferente; porém, só ficaram conhecidas quando indivíduos, que optaram por modificar o ambiente para viverem melhor, estudaram algumas patologias que se tornaram prejudiciais à sociedade. Mundialmente conhecidas pelas comunidades médico-científicas, esses desastres biológicos se disseminam, exponencialmente, pelo intercâmbio de indivíduos; de mercadorias; de animais; e de elementos patógenos, favorecendo sua predominância no ambiente humano e desestruturando o cotidiano de milhões de indivíduos (ABRÃO J, 2020).

Dentre essas mutações, evidencia-se o vírus Influenza A do subtipo H1N1, conhecido pela epidemia denominada Gripe Espanhola (1918-1920). Transmissível pelo ar e pelo contato com pessoas enfermas; causava severos problemas respiratórios a quem tinha o sistema imunológico fraco. Quando esse evento progrediu para pandemia, destacou-se o medo, marcado pela mortalidade de jovens e adultos, e as dúvidas relacionadas à comunidade médico-científica para encontrar uma solução que desse fim à então tragédia. Há fontes que informam que os números de óbitos atingiram de 15 a 25 milhões, outras, indicam que essa pandemia atingiu 40 milhões de indivíduos e provocou impactos na renda per capita, na saúde e na educação de diversos países subdesenvolvidos da época (GURGEL CBFM, 2016; BARRO RJ, et al., 2020; KIND L e CORDEIRO R, 2020).

Cem anos mais tarde, surge o Severe Acute Respiratory Syndrome Coronavirus 2 (SARS-CoV-2) ou Coronavírus da Síndrome Respiratória Aguda Grave 2, popularmente conhecida como Corona Virus Disease19 ou COVID-19 (2019 F), cujo modo de transmissão se assemelha à Gripe Espanhola, porém, apresenta disseminação mais rápida e silenciosa. Mesmo com as recomendações indicadas pela Organização Mundial de Saúde (OMS), constatou-se que, até o dia 17 de junho de 2021, 178.000.567 indivíduos se contaminaram com o vírus; e, ainda que 162.518.980 tenham se recuperado, outros 3.852 .332 sofreram óbitos consequentes da doença adquirida (WORLDMETER, 2021).

Esse número de mortes exigiu investimentos acelerados por parte de governos dos países mais afetados, os quais, juntamente com empresas e laboratórios ligados à saúde, trabalharam na produção de inúmeras vacinas, que, embora em fase experimental, representam uma esperança na solução dos efeitos causados pelo SARS-CoV-2 (LIMA EJF, et al., 2021).

Considerando esse contexto, o presente artigo procurou revisar a bibliografia existente sobre os desastres biológicos referidos acima, o qual se reveste de importância ao mostrar a necessidade em obedecer aos procedimentos recomendados pelos sistemas de saúde para enfrentamento de doenças pandêmicas; e objetiva apresentar, resumidamente, dados relativos às duas pandemias ocorridas no período de 100 anos de diferença uma da outra, salientando que em relação à COVID-19, por ocorrer em tempo presente, os dados estão sempre mudando.

\section{REVISÃO BIBLIOGRÁFICA}

\section{Gripe Espanhola (1916-1918 / 1919-1920)}

Essa patologia foi assim nomeada em razão da imprensa nacional da Espanha ter feito a primeira divulgação da origem e de casos da doença. Muitos historiadores suspeitam que ela surgiu em diferentes locais. Alguns acreditam que foi em um campo de treinamento militar do estado do Kansas, nos Estados Unidos, em 1918, quando os soldados prestaram ajuda aos franceses na Primeira Guerra Mundial/Grande Guerra (1914 - 1918), espalhando-a, assim, pelo restante da Europa (TSOUCALAS G, et al., 2016). Porém, 
estudos de 1933 sugerem que todas as variantes que vieram depois da Gripe Espanhola tiveram sua origem na China, possivelmente devido ao surto epidêmico de uma gripe em 1917, quando houve aumento da venda de carne de porco (GUAN Y, et al., 1996).

Tendo o vírus influenza A do subtipo H1N1 como agente etiológico, originou-se da recombinação do vírus suíno/aviário ou da adaptação direta do vírus aviário em humanos. A transmissão ocorre pelo contato de aerossóis liberados por vias respiratórias de infectados, no ato da tosse. Propenso a surgir em crianças $(<5$ anos) e em idosos (> 65 anos), o quadro clínico pode variar de uma pneumonia aguda, frequentemente associada às pessoas imunocomprometidas ou com histórico de tabagismo; ou de uma pneumonia grave, com probabilidade de surgirem infecções bacterianas. A fisiopatologia do mutagênico é destacada pela obstrução das vias aéreas, distorcendo a capacidade dos pulmões ao realizarem suas trocas gasosas; além de denegrir a estrutura alveolar e a integridade direta das células epiteliais (KALIL AC e THOMAS PG, 2019).

A doença se alastrou pelo mundo em três ondas: duas se originaram em diferentes períodos do ano de 1918, e uma em janeiro de 1919. Nesse meio tempo, a população mundial ficou sabendo quando se observou um segundo surto, fatalmente contaminando milhões de pessoas. Se na primeira onda essa pandemia fosse notificada, o público ficaria apavorado e as campanhas da Grande Guerra, em ambos os lados, seriam afetadas (MARTINI M, et al., 2019). O silêncio foi rompido pela imprensa espanhola durante o segundo surto, período que o número de óbitos e de contaminados aumentou drasticamente (HAYS JN, 1938).

Considerando os três surtos (mundiais) dessa gripe, algumas pesquisas afirmam que o número de mortos atingiu, aproximadamente, 40 milhões, até 1920 (BARRO RJ, et al. 2020). Ainda que outras informações afirmem que a quantidade de óbitos alcançou entre 15 a 25 milhões, a Índia sozinha contribuiu com a maior taxa de mortalidade, estando na frente dos Estados Unidos e de algumas nações da Europa, como a Alemanha e a Inglaterra (GURGEL CBFM, 2016).

Em geral, as áreas mais afetadas foram as grandes metrópoles. No Brasil, por exemplo, relatos dessa gripe já circulavam na imprensa das cidades do Rio de Janeiro/RJ e de Porto Alegre/RS, e nos estados da Bahia e de Pernambuco. No início, os principais jornais não apontavam necessidade de alarde, algo que mudou com o aumento de casos (SANTOS RCG, et al., 2020). Acredita-se que, durante o ápice do segundo surto, mais de 35 mil brasileiros perderam suas vidas. Ademais, chegou-se à conclusão de que o número de contaminados alcançara a marca dos 500 milhões (FUNDAÇÃO OSWALDO CRUZ, 2020).

Embora não exista uma contagem correta sobre o número de mortes, e os dados sejam desconhecidos em relação a cada continente, constatou-se que a China e algumas nações asiáticas sofreram por mais tempo com mutações semelhantes do mesmo vírus, como o Influenza A dos subtipos H2N2 (1957-1958), responsável pela morte aproximada de 1,1 milhões de pessoas (CENTERS FOR DISEASE CONTROL AND PREVENTION, 2019).

As questões socioeconômicas das nações afetadas pela Gripe Espanhola foram duramente alteradas; houve queda abrupta na expectativa de vida e altas taxas de mortalidade em comunidades pobres e desfavorecidas; e a procura por melhores condições de saneamento básico, de vida e de saúde (já precárias) se tornaram mais difíceis de serem acessadas, principalmente devido à extrema pobreza causada pelas guerras e crises econômicas, o que influenciou os governos da época a diminuírem as rendas familiares (FUNDAÇÃO OSWALDO CRUZ, 2020). Além disso, houve redução do nível de escolaridade e da expectativa de vida (KIND L e CORDEIRO R, 2020). Em contrapartida, muitas empresas ligadas aos setores de saúde registraram ganhos e aumento em seus lucros (SPINNEY L, 2017).

Até meados de 1919, o número de contaminados pelo vírus começou a diminuir, ao ponto de desaparecer no mesmo ano, antes da invenção de uma vacina. A literatura sugere que o vírus, depois de várias mutações, tornou-se menos letal; outros especulam que as práticas sanitárias e de isolamento foram suficientes para enfraquecer sua proliferação. Isso a deixou com o rótulo histórico de "pandemia esquecida"; porém, não impediu que novas doenças surgissem das mutações desse vírus, com padrões patofisiológicos diferentes (ALRED WC, 1989).

Considerando os dados explanados acima, verifica-se que o vírus surgiu em determinadas localidades, mas a contaminação em massa atingiu todos os continentes; manifestou-se por surtos epidêmicos e teve 
consequências variadas de acordo com as condições socioeconômicas de cada país. A Figura 1 apresenta um suporte panorâmico desses e de outros aspectos relacionados à Gripe Espanhola.

Figura 1 - Mapa conceitual sobre o histórico de progressão da Gripe Espanhola pelo mundo.

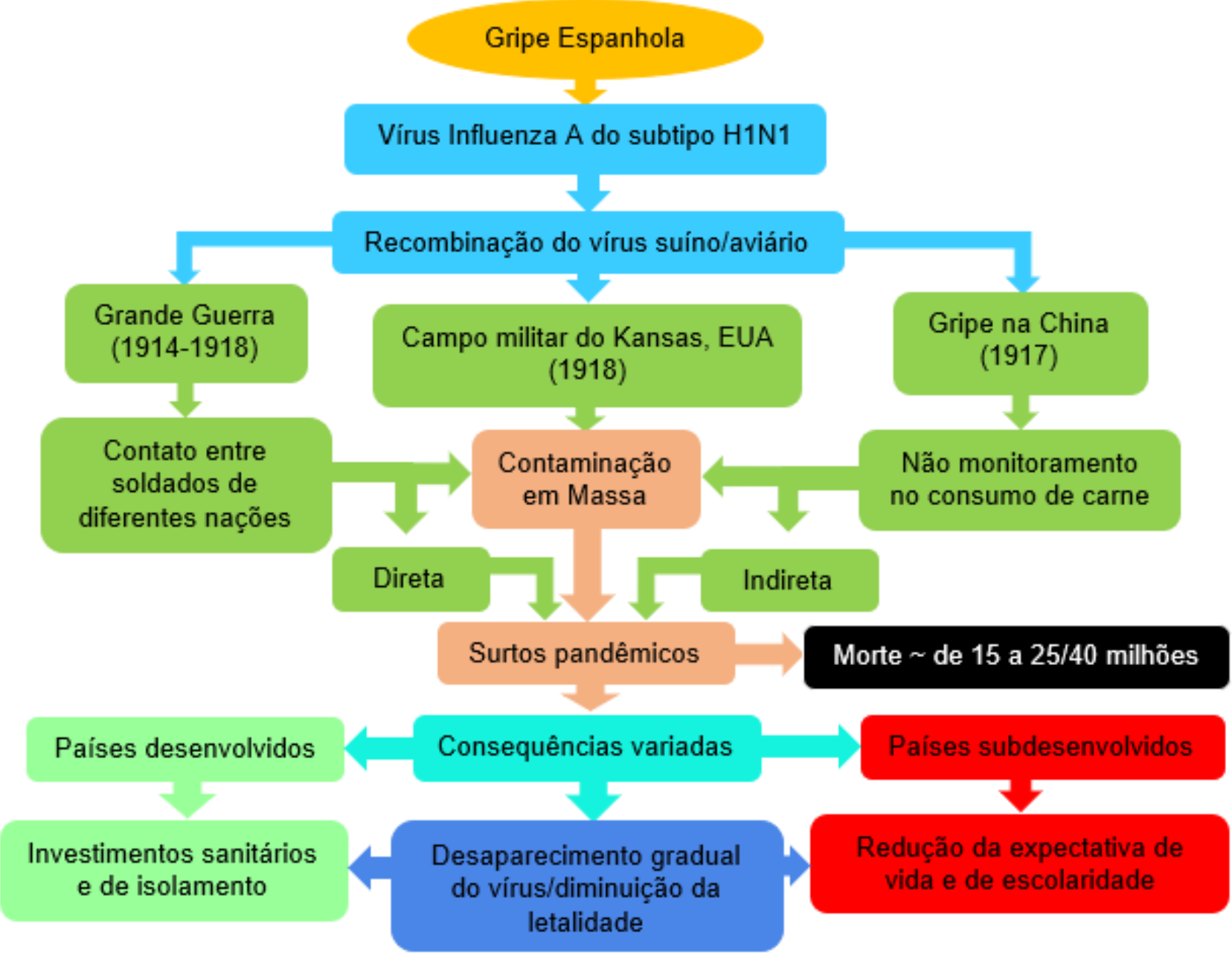

Fonte: Trindade EL e Fortes IG, 2021; dados extraídos de Barro RJ, et al. 2020; Kind L e Cordeiro R, 2020; Fundação Oswaldo Cruz, 2020; Gurgel CBFM, 2016; Guan Y, et al., 1996; Martini M, et al., 2019; Tsoucalas G, et al., 2016.

\section{SARS-CoV-2/COVID-19 (2019 - Presente)}

Sendo da família da Síndrome Respiratória Aguda Grave (SARS), datada de 2002, e da Síndrome Respiratória do Oriente Médio (MERS), de 2012, o vírus SARS-CoV-2 provoca a mais atual pandemia que acomete todos os continentes, com mutações que colocam a sociedade em cenários de medo e desinformação. Originária da cidade de Wuhan, na província de Hubei, China Continental, esse patógeno tem desafiado as comunidades médico-científicas globais, tanto pelas mutações e capacidades proliferativas, quanto pela letalidade que causa aos grupos de risco. Em 2019, a China anunciou ao mundo os primeiros casos surgidos em seu território, indicando-o como o principal epicentro da COVID-19, devido ao transbordamento zoonótico e ao acelerado desmatamento ambiental da região (ACOSTA AL, et al., 2020).

Antes da propagação em humanos, o vírus tinha como principal hospedeiro os morcegos selvagens da região chinesa que apresentavam organismos propensos e vantajosos para a evolução mutagênica do vírus. Durante esse período, esse patógeno conseguiu se utilizar do mecanismo que permite a entrada de proteínas nas superfícies de células saudáveis, principalmente da mucosa do trato respiratório superior (XAVIER AR, et al., 2020). Sem perceberem esse vírus silencioso, as pessoas continuaram se movimentando em locais 
conhecidos como 'mercados úmidos', famosos por distribuírem animais selvagens para consumo. Ainda que alguns não acreditem, muitos pensavam que pangolins, serpentes e morcegos eram portadores do vírus emergente, principalmente por serem fonte alimentícia do país (PERROTA AP, 2020).

Quando o vírus entrou em contato com humanos, acreditava-se que fosse outra pneumonia comum da região, pois nem sempre os sintomas estavam presentes, principalmente em indivíduos saudáveis que tiveram contato com o patógeno durante o período de 2 a 14 dias. Em casos leves, alguns apresentam tosse e dores na garganta, seguidas ou não de diarreia, dores abdominais, febre, calafrios, mialgia, fadiga, cefaleia e/ou perda dos sentidos olfativos e do paladar. Nos casos moderados, a febre e a tosse persistem diariamente, enquanto sintomas como hiporexia e prostração podem surgir. Caso a doença evolua para um estágio mais grave, pessoas imunodeprimidas e idosos são os grupos de risco mais afetados pelo vírus, que pode causar anomalias tanto ao sistema respiratório como aos sistemas circulatório e digestório (BRASIL, 2020).

Todavia, ao se comparar os dados da China (suposto epicentro dessa pandemia) com alguns dos países mais populosos do mundo, verifica-se que esse país asiático apresenta o menor número de contaminados (90.908) e mortos (4.636). Em 2019, após um mês de divulgadas notícias sobre o vírus, este já havia alcançado regiões com maior movimentação comercial e populacional do globo. Desde o início de 2020 até junho de 2021 foram confirmados, aproximadamente, 178.000.567 contaminados; 162.518 .980 recuperados; e 3.852.332 óbitos (WORLDMETER, 2021).

Durante o início dessa pandemia, além dos profissionais da saúde, crianças e idosos, essencialmente os que sofrem com doenças respiratórias, tornaram-se mais vulneráveis com a propagação do vírus, principalmente porque mantinham contato intradomiciliar muito próximo, o que dificultou o isolamento de grupos populacionais específicos. Quando a doença chegou ao Brasil, muitos dos indivíduos do grupo de risco tiveram que configurar novas estratégias para o convívio com seus entes diante da quarentena que estava por vir (BORGES GM e CRESPO CD, 2020).

Após o anúncio da OMS sobre a pandemia viral, milhões de cidadãos passaram por severas mudanças para se adaptarem às normas exigidas pelos governos que enfrentavam número crescente de contaminados pela COVID-19 (BRASIL, 2020). Segundo a própria OMS, o desempenho de atividades e a participação social são elementos fundamentais que condicionam uma vida saudável, algo que essa pandemia comprometeu, pois muitas nações não estavam preparadas para as mudanças que vieram com a disseminação do vírus (SILVA TR, et al., 2020). Alguns países, urgentemente, colocaram em prática as medidas profiláticas e utilizaram plataformas online para conscientizar a população, o que, além de ajudar a diminuir o medo diante do desastre biológico, contribuiu para a redução dos números de contaminados e mortos (EFFENBERGER M, et al., 2020).

Nem todos os países puderam auxiliar grande parte de seus cidadãos, principalmente aos que dependiam de um emprego que exigia sair de seu domicílio para trabalhar. O Brasil, infelizmente, foi um desses países em que as medidas profiláticas e o sistema de saúde não foram efetivos para conter a proliferação do SARSCoV-2, apesar de possuir recursos naturais em abundância, úteis às pesquisas e às ações de enfrentamento ao vírus, e necessários à estabilização da economia brasileira, aspecto importante no combate a qualquer doença (AQUINO EML e LIMA RTRS, 2020). Além de representar alto custo de vida e causar impactos nas condições de renda da população, provocou choques de oferta e demanda em atividades humanas, influenciando negativamente nos índices de consumo e emprego (GARCÍA AR e PRECIADO ALJ, 2021).

Até o momento, governos de algumas nações vêm oferecendo ao Brasil ajuda para setores da saúde, visando melhorar o atendimento aos infectados para não sobrecarregar as unidades, como hospitais. Porém, o número de enfermos passa do limiar de suporte de atendimento dos centros de saúde. Com esse quadro, o número de mortes tende a crescer exponencialmente e os recursos importantes para manter os pacientes vivos tendem a se esgotar. Dificilmente, o pico epidêmico será revertido se os governos de cada país não continuarem a investir nos sistemas de saúde, como no Brasil, onde a quantidade de casos, não necessariamente graves, têm tendencia a piorar (BRASIL, 2021).

Conforme exposto acima, verifica-se que as mutações gênicas do SARS-CoV-2 e o desmatamento favoreceram o alojamento do vírus em animais selvagens, cujo patógeno contaminou humanos e se 
disseminou pelos continentes por rotas comerciais; e as consequências, como o número de mortos, relacionam-se à forma como os países enfrentaram e enfrentam a pandemia. A Figura 2 oferece um suporte panorâmico desses elementos.

Figura 2 - Mapa conceitual sobre o histórico de progressão do SARS-CoV-2.

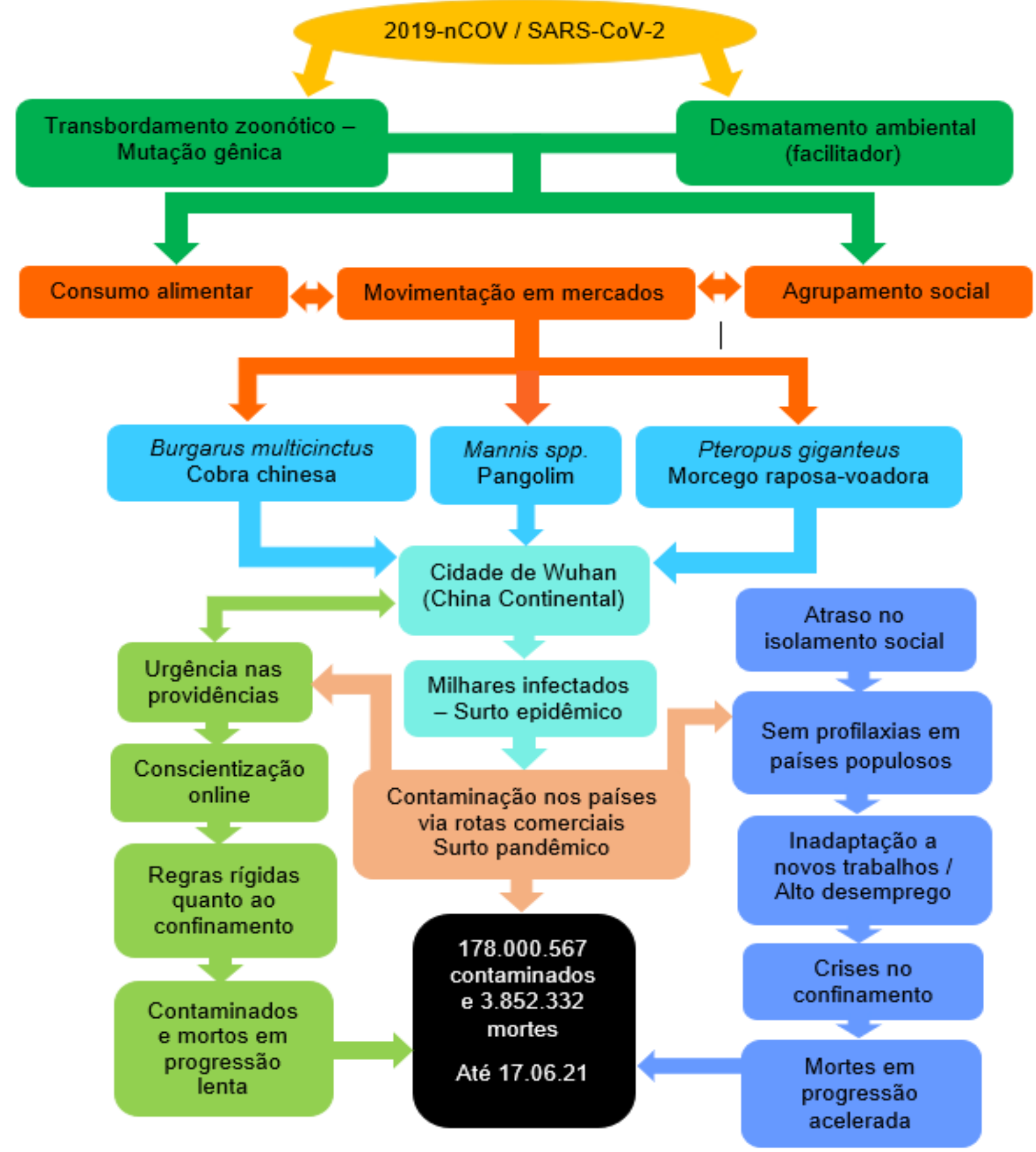

Fonte: Trindade EL e Fortes IG, 2021; dados extraídos de Acosta Al, et al., 2020; Borges GM e Crespo CD, 2020; Effenberger M, et al., 2020; Perrota AP, 2020; Silva TR, et al., 2020; Worldmeter, 2021.

De modo geral, o SARS-CoV-2 trouxe desafios à ciência, que tem desenvolvido metodologias para tratar os enfermos e encontrar a 'cura' para a doença. As vacinas como método terapêutico preventivo têm sido 
notícia em todo os países; e algumas estão sendo aplicadas em fase experimental pelas equipes de saúde das nações afetadas. Até meados de 2020, já se somavam mais de 33 países desenvolvendo pesquisas para a produção de vacinas, principalmente por terem atingido um avanço tecnológico e maior variedade de profissionais qualificados para essa atividade. A empresa laboratorial americana Pfizer conseguiu, desde julho/2020, que mais de 30 mil indivíduos participassem da fase de testes, e está em atividade desde o final de outubro de 2020 (LIMA EJF, et al., 2021).

As vacinas CoronaVac da China, com quem o instituto brasileiro Butantan faz parceria científica; Sputnik $V$ da Rússia e da empresa AstraZeneca (Reino Unido), prosseguem para a fase 3 dos testes em humanos (LIMA EJF, et al., 2021). Além das vacinas, cientistas da China, EUA, Irã e de outros países desenvolvem estudos com células tronco mesenquimais que, apesar de ajudarem especificamente aos pacientes internados, contribuem para a terapia avançada do tipo celular, com bons resultados em pacientes contaminados pelo vírus da COVID-19 (GOLCHIN A, et al., 2020). Tempos depois, essa iniciativa foi aprovada no Brasil para futuros atendimentos experimentais (ANVISA, 2020).

\section{Pontos comuns entre as pandemias}

Tanto o vírus da gripe quanto o da síndrome respiratória se revelaram altamente transmissíveis; de rápido contágio; provocando mortes na casa de milhões e acometendo a todas as faixas etárias. Porém, enquanto a pandemia passada atingiu muitos jovens, a atual atinge mais pessoas consideradas de grupos de risco, como idosos (TEXEIRA CP, et al., 2020; KIND L e CORDEIRO R, 2020).

Um fator importante utilizado pela equipe de saúde e de governos dos países mais atingidos com as pandemias aqui explanadas é o serviço de comunicação. Algumas informações sobre a Gripe Espanhola e, principalmente, sobre a COVID-19 não foram bem explicadas para mobilizar o público; tanto a ignorância quanto a descrença foram maiores que as tendências médicas de cada época, o que faz uma doença se alastrar, até haver conscientização tardia e provocar mais contaminações (TEXEIRA CP, et al., 2020; p. 16). Ainda que o mundo conte com tecnologia avançada e redes sociais para prestar informações em tempo real a todos os locais do planeta, grande parte das informações geraram, e ainda geram, polaridades que podem afetar o controle das pandemias (HOPPE MFF, et al., 2020).

Esses dois desastres biológicos mudaram a rotina das pessoas, que tiveram de se adaptar às novas regras de convívio em grupo, como distanciamento e isolamento social, para se protegerem de uma crise sanitária gerada pelo quadro de pandemia. Nesse contexto, surge a crise econômica, pois os setores de produção, de serviços e de comércio se veem obrigados a parar, parcial ou totalmente, com suas atividades, o que afeta 0 mercado de emprego, impacta no provimento de subsistência da população mundial, culmina na concentração da riqueza e aumento da pobreza. Na pandemia atual, fruto dessa crise, aumentou o número de moradores de rua e de pessoas em situação de vulnerabilidade social (SILVA MHA e PROCÓPIO IM, 2020).

\section{CONSIDERAÇÕES FINAIS}

Os avanços tecnológicos e científicos nem sempre impedem desastres biológicos, mas amenizam suas consequências se utilizadas práticas profiláticas como ocorrem em períodos pandêmicos, que têm o dom de causar mudanças no comportamento e padrão de vida das pessoas. As mortes provocadas por esses desastres retratam como cada nação gerencia e controla os surtos endêmicos. No passado, as ações de contenção dessas patologias foram úteis; porém, no presente, são insuficientes. É preciso utilizar tecnologias avançadas e buscar caminhos seguros, como as vacinas, que, embora não tragam imunização coletiva, são a esperança para futuras gerações. Os dados relativos às pandemias aqui abordadas são importantes para conscientizarem e levarem os indivíduos a praticarem as medidas profiláticas de combate à COVID-19.

\section{REFERÊNCIAS}

1. ABRÃO J. História, Memória e Comportamento Sociais em Tempos de COVID-19. História em Revista, Pelotas, 2020; 2: $209-229$ 
2. ACOSTA AL, et al. Interfaces à transmissão e spillover do coronavírus entre florestas e cidades. Estudos avaliativos, 2020; 34(99).

3. ALRED WC. America's Forgotten Pandemic: The Influenza of 1918. Nova Edição. Cambridge University Press, 1989; 3.

4. ANVISA. Anvisa aprova pesquisa com células-tronco para Covid-19. 6 de novembro de 2020. Disponível em: <https://www.gov.br/anvisa/pt-br/assuntos/noticias-anvisa/2020/anvisa-aprova-pesquisa-com-celulas-tronco-paracovid-19?_ga=2.109511427.704098181.1623251943-383824001.1623251943>. Acessado em 16 de janeiro de 2021.

5. AQUINO EML, LIMA RTRS. Medidas de distanciamento social no controle da pandemia de COVID-10: potenciais impactos e desafios no Brasil. Ciência \& Saúde coletiva, 2020; 25(suppl 1).

6. BARRO RJ, et al. The coronavirus and the great influenza pandemic: lessosn from the "spanish flu" for the coronavirus's potencial effects on mortality and economic activity. NBER Working Paper, 2020; 26866.

7. BORGES GM, CRESPO CD. Aspectos demográficos e socioeconômicos dos adultos brasileiros e a COVID-19: uma análise dos grupos de risco a partir da Pesquisa Nacional de Saúde, 2013. Cadernos de Saúde Pública, 2020; 36(10).

8. BRASIL. Ministério da Justiça. Governo Federal. Dossiê: Direito e Justiça em Tempos de Pandemia. Revista de Seção Judiciária do Rio de Janeiro. 2 de julho de 2020 . Disponível em: <http://lexcultccjf.trf2.jus.br/index.php/revistasjrj/issue/view/17/Edi\%C3\%A7\%C3\%A30\%20Completa\%20-

\%20Dossi\%C3\%AA\%20Coronav\%C3\%ADrus>. Acessado em 31 de janeiro de 2021.

9. BRASIL. Ministério da Ciência, Tecnologia e Inovações. Governo Federal. Modelo matemático é aplicado para prever a possível evolução da covid-19. 13 de maio de 2020. Disponível em: Disponível em: <https://www.gov.br/observatorio/pt-br/assuntos/noticias/evolucao-pandemia-astronomia>. Acessado em $31 \mathrm{de}$ janeiro de 2021.

10. BRASIL. Ministério da Saúde. Governo de Santa Catarina. Manual de Orientações da COVID-19 (vírus SARS-CoV2). 2020. Disponível em: <https://www.saude.sc.gov.br/coronavirus/arquivos/Manual_23-10-atualizado.pdf>. Acessado em 30 de janeiro de 2021.

11. CENTERS FOR DISEASE CONTROL AND PREVENTION. 2019. The Deadliest Flu: The Complete Story of the Discovery and Reconstruction of the 1918 Pandemic Virus. Disponível em: <https://www.cdc.gov/flu/pandemicresources/reconstruction-1918-virus.html>. Acessado em 13 de janeiro 2021.

12. EFFENBERGER M, et al. Association of the COVID-19 pandemic with Internet Search Volumes: A Google Trends TM Analysis. Int J Infect Dis, 2020; 95:192-197.

13. FUNDAÇÃO OSWALDO CRUZ. 2020. A Fiocruz em dois tempos: nas pandemias da gripe espanhola e da Covid-19. Disponível em: <https://agencia.fiocruz.br/fiocruz-em-dois-tempos-nas-pandemias-da-gripe-espanhola-e-da-covid19>. Acessado em 2 de fevereiro de 2021.

14. FUNDAÇÃO OSWALDO CRUZ. 2020. Diálogos sobre acessibilidade, inclusão e distanciamento social: territórios existenciais na pandemia. Disponível em: <http://www.ideiasus.fiocruz.br/portal/publicacoes/livros/Livro_Dialogos_sobre_Acessibilidade_Inclusao_e_Distancia mento_Social_1ed.pdf>. Acessado em 17 de junho de 2021.

15. GARCIA AR, PRECIADO ALJ. COVID-19 and Economics Forecasting on Advanced and Emerging Countries. EconoQuantum, 2021; 18(1).

16. GUAN Y, et al. Emergence of Avian H1N1 Influenza Viruses in Pigs in China. Journal of Virology, nov. 1996; 80418046.

17. GOLCHIN A, et al. Mesenchymal Stem Cell Therapy for COVID-19: Present or Future. Stem Cell Reviews and Reports, 2020; 16(3): 427-433.

18. GURGEL CBFM. 1918: a gripe espanhola desvendada?. Sociedade Brasileira de Clínica Médica, 2013; 11(4).

19. HAYS JN. The Burdens of Disease. University of Chicago, 1938; 277p.

20. HOPPE MFF, et al. Modelagem de dados da covid-19 para uma cidade brasileira. VI ENANPARO, Limiaridade: processos e práticas em Arquitetura e Urbanismo, 2020; 13p.

21. KALIL AC, THOMAS PG. Influenza virus-related critical illness: pathophysiology and epidemiology. Critical Care, 2019; 23(258).

22. KIND L, CORDEIRO R. Narrativas sobre a morte: a gripe espanhola e a covid-19 no Brasil. Psicologia e Sociedade, $2020 ; 32$.

23. LIMA EJF, et al. Vacinas para COVID-19 - o estado da arte. Revista Saúde Materno Infantil, 2021; 21 (supl 1).

24. MARTINI M, et al. The Spanish Influenza Pandemic: a lesson from history 100 years after 1918. Journal of Preventive Medicine and Hygiene, 2019; 60(1): E64-E67.

25. PERROTA AP. Serpentes, morcegos, pangolins e 'mercados úmidos' chineses: Uma crítica da construção de vilões epidêmicos no combate à Covid-19. DILEMAS: Revista de Estudos de Conflito e Controle Social, 2020; p. 1-6.

26. SANTOS RCG, et al. Educação em tempos de pandemia: uma narrativa da gripe espanhola à Covid-19. Revista de Ciências Humanas e Sociais, 2020; 6(2): 8.

27. SILVA MHA, PROCÓPIO I M. A fragilidade do sistema de saúde brasileiro e a vulnerabilidade social diante da COVID19. Revista Brasileira em Promoção da Saúde, 2020; 33(10724).

28. SILVA TR, et al. Aprendendo a lidar com as mudanças de rotina devido ao Covid-19: Orientações Práticas para Rotinas. Revista Internacional Brasileira de Terapia Ocupacional, 2020; 4(3).

29. SPINNEY L. Pale rider - The Spanish flu of 1918 and how it changed the world. 2017; p. 167-169.

30. TEXEIRA CP, et al. Covid-19 e atenção primária: as experiências nos territórios (Rede PROFSAÚDE). PROFSAÚDE, 2020; $23: 142$.

31. TSOUCALAS G, et al. The 1918 Spanish Flu Pandemic, the Origins of the H1N1-virus Strain, a Glance in History. European Journal of Clinical and Biomedical Sciences, 2016; 2(4): 23-28.

32. WORLDMETER. $2021 . \quad$ Covid-19 coronavirus pandemic. <https://www.worldometers.info/coronavirus/c>. Acessado em 17 de junho de 2021.

33. XAVIER AR, et al. COVID-19: manifestações clínicas e laboratoriais na infecção pelo novo coronavírus. Jornal Brasileiro de Patologia e Medicina Laboratorial, 2020; 56. 